\title{
Composite indicator for railway infrastructure management
}

\author{
Stephen M. Famurewa • Christer Stenström • \\ Matthias Asplund · Diego Galar • Uday Kumar
}

Received: 27 March 2014/Revised: 15 April 2014/Accepted: 17 April 2014/Published online: 26 August 2014

(C) The Author(s) 2014. This article is published with open access at Springerlink.com

\begin{abstract}
The assessment and analysis of railway infrastructure capacity is an essential task in railway infrastructure management carried out to meet the required quality and capacity demand of railway transport. For sustainable and dependable infrastructure management, it is important to assess railway capacity limitation from the point of view of infrastructure performance. However, the existence of numerous performance indicators often leads to diffused information that is not in a format suitable to support decision making. In this paper, we demonstrated the use of fuzzy inference system for aggregating selected railway infrastructure performance indicators to relate maintenance function to capacity situation. The selected indicators consider the safety, comfort, punctuality and reliability aspects of railway infrastructure performance. The resulting composite indicator gives a reliable quantification of the health condition or integrity of railway lines. A case study of the assessment of overall infrastructure performance which is an indication of capacity limitation is presented using indicator data between 2010 and 2012 for five lines on the network of Trafikverket (Swedish Transport Administration). The results are presented using customised performance dashboard for enhanced visualisation,
\end{abstract}

S. M. Famurewa $(\bowtie) \cdot$ C. Stenström · M. Asplund · D. Galar ·

U. Kumar

Division of Operation and Maintenance Engineering Luleå

University of Technology, Luleå, Sweden

e-mail: stefam@ltu.se

S. M. Famurewa $\cdot$ C. Stenström · D. Galar · U. Kumar

Luleå Railway Research Centre, Luleå, Sweden

M. Asplund

Trafikverket (the Swedish Transport Administration), Luleå, Sweden quick understanding and relevant comparison of infrastructure conditions for strategic management. This gives additional information on capacity status and limitation from maintenance management perspective.

Keywords Composite indicator - Infrastructure capacity · Fuzzy logic · Performance dashboard · Strategic decisions . Line integrity

\section{Introduction}

An essential task in railway infrastructure management is the evaluation of the network capacity. The standard method for the calculation of railway capacity follows criteria and methodologies from international perspective [1]. The use of simulation tools and techniques has enhanced the analysis of railway capacity for improvement for infrastructure managers [2-5]. These tools have not only supported the estimation of capacity consumed but also have helped in evaluating how it has been utilised and how it can be better utilised. An efficient management of infrastructure capacity should accommodate different views and requirements relating to customer need, infrastructure condition, timetable planning and actual operating conditions [1].

Generally, some factors have been identified as constraints to achievable capacity since they apparently limit capacity enhancement attempts in traffic management. These limitations include priority regulations, timetable structure, design rules, environmental, safety and technical constraints [1]. In Sweden, the infrastructure manager makes an annual evaluation of the infrastructure capacity situation and utilisation. This evaluation gives the track occupation time on all the line sections and 
also capacity limitation due to additional train path demands that cannot be met because of excessively high track occupation time [6]. For example, in 2012 about $7 \%$ of all the line sections in the Swedish railway network had an average daily consumption greater than $80 \%, 15 \%$ line sections between $60 \%$ and $80 \%$, and $77 \%$ of the line sections with less than $60 \%$ track occupation time [6]. Furthermore, capacity limitation is based on the level of capacity consumption in relation to additional request for traffic volume, weight per metre, axle load and train paths.

Addressing railway capacity from the point of view of infrastructure integrity assurance is not well addressed by the present capacity assessment procedures. It is, therefore, a subject of interest in maintenance research. An issue that is addressed in this study is the extension of capacity analysis to quantification of health condition of railway infrastructure under certain traffic profile. Such integrity indicator or measure of infrastructure performance gives an additional measure of capacity limitation on a line. Using infrastructure performance indicators in capacity analysis help to relate maintenance and renewal functions to the capacity condition of a network and also facilitate effective maintenance decision making.

Conventionally, the assessment and analysis of infrastructure performance is carried out using individual indicators such as punctuality, frequency of failure, track quality index, etc., separately. Extensive studies on the identification and management of performance indicators which are related to railway infrastructure have been studied by Stenström et al. [7] and Åhrén and Parida [8]. However, such indicators should be aggregated to present the condition or integrity of infrastructure in a holistic way such that it can be related to the capacity condition of the infrastructure. To this end, railway infrastructure performance indicators and the process of aggregating them as a composite indicator are studied in this paper.

The argument surrounding the use of composite indicator has been addressed by Galar et al. [9], where the strengths and weakness of composite indices are highlighted. Composite indicator has been proven to be a tool for benchmarking and strategic decision making [9-12], and can be used for monitoring maintenance and renewal in a capacity enhancement programme. A detailed technical guideline for the construction of high-quality composite indices was given by Nardo et al. [10]. In addition to this, the framework to guide the development of composite indices in the field of asset management has been presented by Galar et al. [9]. The contribution of this paper is the development of composite performance indicator for infrastructure management, useful for relating maintenance functions to the capacity condition of a network and facilitating effective maintenance decision making.

The rest of the paper is organized as follows: Sect. 2 presents the framework for computing composite indices, and Sect. 3 describes a fuzzy logic approach for the development of fuzzy composite indicator (FCI). The details of the case study are presented in Sect. 4, and the results and discussion are presented in Sect. 5. The final section presents the concluding remark of this paper.

\section{Framework for computing composite indicator}

The integrity and usefulness of composite indices depend largely on the framework which guides the computation process. To develop a composite indicator with acceptable quality and approximate characterisation of the state of a physical asset, it is essential to deploy a well-structured guideline that addresses the core issues. This will prevent both overestimation and underestimation of the overall state of the asset. Figure 1 provides a framework for the computation of composite indicator as required for the management of physical assets such as railway infrastructure. The core issues of the framework are as follows:

- Selection of indicators

- Selection of aggregation technique

- Selection of weighing method

- Aggregation process

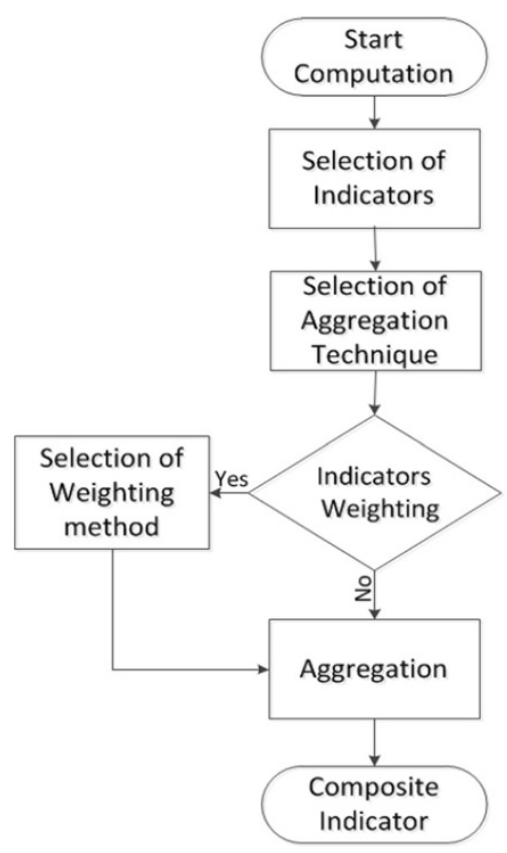

Fig. 1 Framework for composite indicator computation 


\subsection{Selection of indicators}

Systems of performance indicators for general physical asset management and precisely for railway infrastructure management have been presented in different literatures [7, 8, 13-15]. These indicators are used for the assessment of maintenance contracts, infrastructure integrity and service quality, and also prompt alert for quick intervention. All indicators are, however, not required in the development of a composite indictor, and there is need to use appropriate criteria in the selection of most relevant indicators. The indicators selected should present adequate information necessary for the computation of a reliable integrity index. In the case study, the selected indicators cover the following:

- indication of both functional failure and reliability of the infrastructure (failure frequency);

- indication of service performance in terms of quality of service which is a measure of the customer satisfaction (punctuality or delay);

- indication of safety performance (inspection remarks); and

- indication of functional degradation and durability of the infrastructure (Track quality index).

\subsubsection{Failure frequency}

This is the count of the number of times a component or system on a line is not able to perform the required function. Failure categories suitable for use in railway applications have been classified into three classes: immobilising failure, service failure and minor failure. In this study, the count of failure is limited to functional failure that interrupts the traffic flow leading to significant and major consequences on either economy or operation. Minor failures that do not prevent a system or line from achieving its specified performance or cause train delay are not considered in the failure count because of the extensive and complex nature or railway systems.

\subsubsection{Punctuality}

This is an aspect of operational consequence arising from interruption in the planned travel times of trains due to the reduction or termination of the functional performance of the infrastructure. It is measured either in terms of minutes of delay or the number of trains that arrived earlier or later than schedule. Further, the philosophy of punctuality differs from one infrastructure manager to another; hence, it is common to use non-negative arrival delay which is estimated after 5 min post the scheduled arrival time.

\subsubsection{Track quality index (TQI)}

This is a value that characterizes the track geometry quality of a track section based on the parameters and measuring methods that are compliant with the standard. Since there are different kinds of analyses and uses of track quality geometry data, therefore the aggregation and computation method for track quality index could be on detailed, intermediate and overview levels [25]. This study utilized an overview TQI which summarizes a large amount of data for strategic decisions or for long-term network management by infrastructure managers. The track quality index used in this study was selected for the following reason: to reflect the integrated track quality view by combining standard geometry quality parameters, to identify with the standard quality index used by the infrastructure manager (Trafikverket), and to provide for easy fuzzy description by experts using linguistic term. Equation 1 shows the formula used for the evaluation of TQI, and Fig. 2 gives a hypothetical illustration and description of TQI values. A track with a perfect geometry quality has a TQI equal to 150 but it degrades over time based on traffic loading, formation condition, track layout and other factors.

$\mathrm{TQI}=150-\frac{100}{3}\left(\frac{\sigma_{\mathrm{LL}}}{\sigma_{\mathrm{TH} \_\mathrm{LL}}}+2 \frac{\sigma_{\mathrm{A} . \mathrm{C}}}{\sigma_{\mathrm{TH} \_\mathrm{A} . \mathrm{C}}}\right)$,

where $\sigma_{\mathrm{LL}}$ and $\sigma_{\mathrm{A} . \mathrm{C}}$ denote the standard deviations of the longitudinal level, and of the combined alignment and cross level; $\sigma_{\mathrm{TH} \_\mathrm{LL}}$ and $\sigma_{\mathrm{TH} \_ \text {A.C }}$ represent the comfort threshold of the parameters.

\subsubsection{Inspection remarks}

Examination of a system by observing, testing or measuring its characteristic condition parameter at predetermined intervals is an essential aspect of operation and maintenance. Such an inspection could be a visual inspection or non-destructive testing such as ultrasonic inspections, eddy current checks, track geometry measurement, laser inspections and other dedicated techniques. For the railway infrastructure, inspection is based on the traffic volume and the line speed. It is a usual practice that reports are generated as inspection remarks after inspection. The remarks are classified into priority levels on the basis of the seriousness of the observation. The priorities of the remarks considered in the case study are acute and weekly categories [16].

In the selection process, it is important to carefully address likely correlations between the indicators, especially if a linear or geometric aggregation method is used. Table 1 shows that there is a significant correlation between failure frequency and delay time (using the 
Table 1 Spearman's rho and $p$ value for statistical correlation between the indicators

\begin{tabular}{lrrrr|rrrrr}
\hline r & FF & Delay & \multicolumn{1}{c}{ IR } & TQI & $p$ value & FF & Delay & IR & TQI \\
\hline FF & 1.00 & 0.79 & -0.09 & 0.21 & FF & 1.00 & 0.00 & 0.69 & 0.36 \\
Delay & 0.79 & 1.00 & -0.15 & 0.20 & Delay & 0.00 & 1.00 & 0.51 & 0.38 \\
IR & -0.09 & -0.15 & 1.00 & -0.42 & IR & 0.69 & 0.51 & 1.00 & 0.06 \\
TQI & 0.21 & 0.20 & -0.42 & 1.00 & TQI & 0.36 & 0.38 & 0.06 & 1.00 \\
\hline
\end{tabular}

FF failure frequency; TQI track quality index, IR inspection remarks

Spearman's rho for monotonic relationship and $p$ value for statistical significance), whereas other indicators have neither a linear nor a non-linear correlation. However, approximately $20 \%$ of the variation in the delay time is not explained by the failure frequency, showing that operational consequence in terms of delay is not fully explained by the failure frequency. In addition, in the field of traffic management, the total delay caused by infrastructure integrity is a function of the traffic volume and homogeneity, downtime (summation of active maintenance time and waiting time) and frequency of failure. Thus punctuality although correlated with the failure frequency is considered in the construction of the FCI, since it gives additional information on the consequence of failure on customer, which is not explained by the frequency of failure.

\subsection{Aggregation of indicators}

Considering the need to integrate different variables and indicators in a single indicator, several methodologies/ techniques have been developed and deployed to aggregate such indicators. The available techniques and methods for the aggregation of indicators include the following:

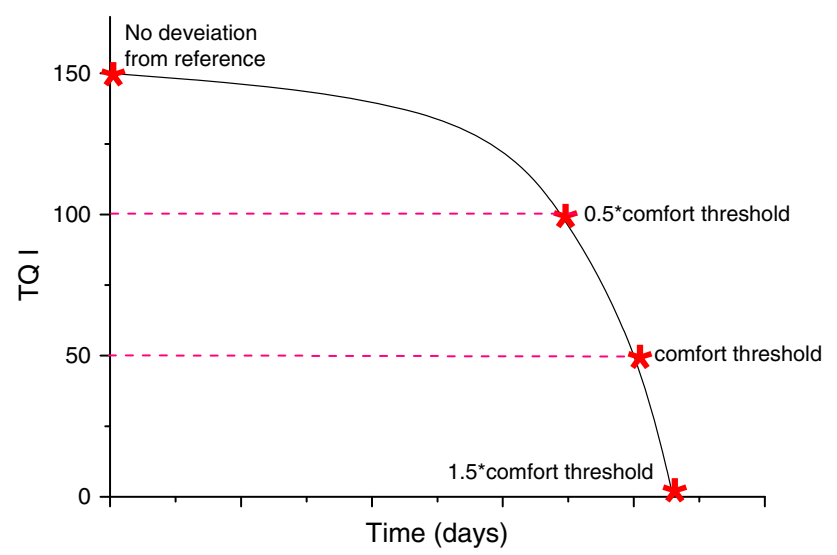

Fig. 2 Description of track quality index
- Linear aggregation or Simple Additive Weighting $(S A W)$ method- It is useful when all indicators have comparable measurement units and all physical theories are respected or when they can be normalised. Weak indicators can be masked or compensated by other strong indicators; thus this method requires careful implementation.

- Geometric method- It can be used for indicators with non-comparable ratio scale where reduced measure of compensation is required in the aggregation of the constituent indicators.

- Multi-criteria approach with specific rules- This is basically used when a number of criteria/indicators are involved in the computation and when highly different dimensions are aggregated in a composite indicator. Basically it entails an evaluation of $\mathrm{N}$ alternatives using $\mathrm{C}$ criteria, and then aggregating the result using special rules and theories. Examples include: Analytic hierarchy process (AHP), ELECTRE, TOPSIS, VIKOR, etc.

- Soft computing approach-This approach is used when the constituent indicators can be expressed in linguistic terms and then aggregated using computing with words (such as fuzzy logic). The advantages of this approach include the following: modelling of non-linear behaviour; accommodation of imprecision in the normalisation of the data; aggregation without subjective allocation of weights to the indicators; ranking of alternatives in such a way that the output value can be treated as the health value or integrity index. On the other hand, the reliability of the composite indicator depends on the experience of the expert group; it requires additional information to explain the underlying physical phenomenon responsible for the variation of its value.

The fuzzy logic approach is preferable in the context of this article, since the problem being addressed relates more to assessing the overall integrity of line over time for strategic purpose than ranking them based on their integrity. 


\section{Fuzzy logic method}

Fuzzy logic is based on imprecise human reasoning and exploits the tolerance for imprecision to solve complex problems and support decision making on complex systems $[17-19,20]$. The underlying technique in fuzzy logic is computing with words or linguistic variables. The concept of linguistic variables creates the possibility for an approximate characterisation of processes which are too complex or too imprecise, by conventional quantitative analysis. It is a logical way to map an input space to an output space using a fuzzy set [21]. The capability of a fuzzy system for making implications between antecedents and consequents makes it appropriate for complex system analysis [18, 19]. This explains the application of fuzzy logic in the aggregation of indicators for the computation of a composite indicator suitable for strategic purposes.

\subsection{Fuzzy inference system}

The fuzzy inference system (FIS) is a process of formulating the mapping from given input parameters to an output using a natural language technique known as fuzzy logic [11]. Basically, the input parameters into FIS can either be fuzzy or crisp inputs, and the outputs are mostly fuzzy sets, but can be transformed to crisp outputs, since this is preferable for easy decision making. An FIS can be decomposed into three phases-input phase, aggregation phase and output phase as shown in Fig. 3.

The input phase involves a linguistic description of the parameters and fuzzification to obtain a fuzzy set of each input parameter. The aggregation phase has two steps that facilitate the mapping of the input parameters to output, i.e. inference rules and fuzzy set operation. The output phase defines the fuzzy set of the output parameter and also presents the final indicator in either fuzzy or non-fuzzy value [18].

\subsection{Membership function}

The membership of an element from the universe in a fuzzy set is measured by a function that attempts to describe vagueness and ambiguity due to the nature of the boundaries of the fuzzy sets. Elements of a fuzzy set are mapped to a space of membership values using a function-theoretic form [18]. This function associates all elements of a fuzzy set to a real value within the interval $0-1$.

\subsection{Aggregation process}

The aggregation process involves two operations known as inference rules and fuzzy set operations. Fuzzy inference rule is a collection of linguistic statements that describe how the FIS should make a decision regarding the integration of the input into an output [18]. These rules form the basis for the FIS to obtain the fuzzy output that can be transformed into a non-fuzzy numerical value which are required in a no-fuzzy context. This is mainly based on the concepts of the fuzzy set theory and relations; it uses linguistic variables as its antecedents and consequents. The antecedents are the IF expressions which should be satisfied. The consequents are the THEN statements which are inferred as output, when the IF antecedents are satisfied [22]. The common inference rules are formed by general statements such assignment, conditional or unconditional statements [22]. The connectors used in the fuzzy rulebased system are 'OR' and 'AND' and their operations are described as follows:

$$
\begin{aligned}
& \text { Fuzzy set } \underset{\sim}{A}=\left(x, \underset{\sim}{\mu_{A}}(x)\right), \quad x \in X, \\
& \text { Fuzzy set } \underset{\sim}{B}=\left(x, \underset{\sim}{\mu_{B}(x)}\right), \quad x \in X,
\end{aligned}
$$

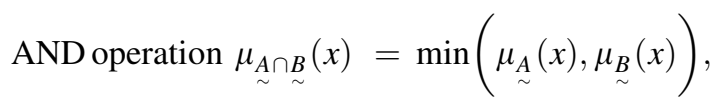

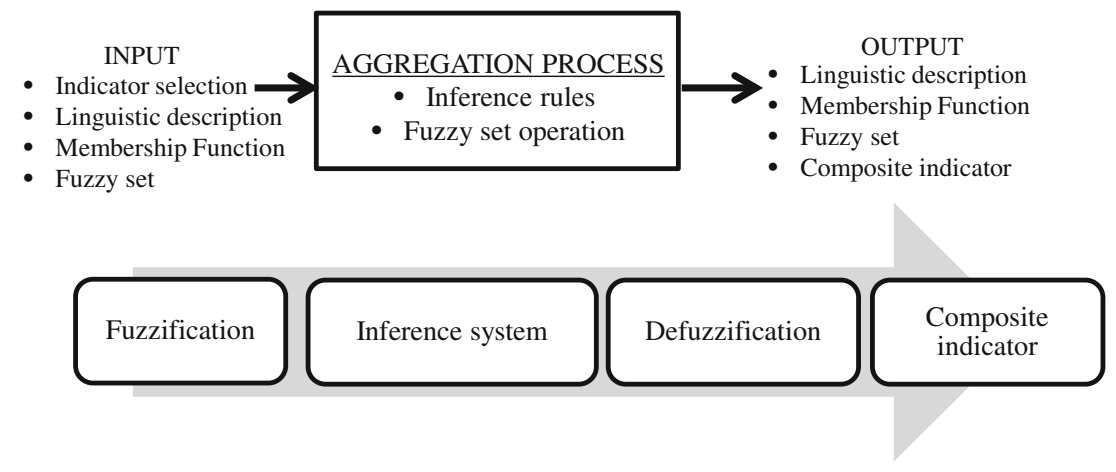

Fig. 3 Fuzzy inference system for computation of composite indices 
OR operation $\underset{\sim}{\mu_{\sim} \cup \underset{\sim}{B}}(x)=\max \left({\underset{\sim}{\mu}}_{A}(x), \underset{\sim}{\mu_{B}}(x)\right)$.

\subsection{FIS approach}

The most common approaches used in fuzzy inference systems are the Mamdani and Takani Sugeno approaches [22]. Basically, the working principle of Mamdani FIS can be explained as follows $[11,18]$ :

1. Selection of linguistic quantifier and development of membership function to describe the indicators in fuzzy sets.

2. Conversion of the crisp indicator into a fuzzy element using fuzzification method to obtain the membership values of each linguistic quantifier.

3. Aggregation of the membership values on the antecedent (IF) parts to obtain the firing strength (weight) of each rule. Usually this is done in a fuzzy intersection operation using an AND operator or the minimum implication as shown in Eq. 2.

4. Generation of the consequents from the different combinations of antecedents using the established fuzzy inference rules.

5. Aggregation of the obtained consequents (fuzzy set) from each rule to obtain a single output fuzzy set using an OR operator or the maximum method for union of fuzzy sets. See Eq. 3.

6. Defuzzification of the output fuzzy set using the centre of mass method or the centre of gravity under the curve of the output fuzzy set. $Z^{*}$ is the defuzzified value or centre of mass obtained from the algebraic integration of the membership grade of element $\mathrm{Z}$ in the output fuzzy set $\mathrm{C}$ using Eq. 4 .

$Z^{*}=\frac{\int \mu_{c}(z) \times z \mathrm{dz}}{\int \mu_{c}(z) \mathrm{d} z}$.

\subsection{Composite indicator for railway management}

There is a need to combine the information provided by simple output indicators to facilitate strategic decision making. Thus four indicators have been selected to develop a composite indicator for the assessment of the integrity of railway infrastructure. The selected indicators are hereafter referred to as the input parameters of a FIS, which are aggregated to obtain an indicator known as FCI. The FCI is graduated from 0 to 1 to indicate the integrity of the infrastructure, which is afterwards described by five linguistic terms or fuzzy sets. The selected linguistic terms are considered adequate for a simplified scaling of the FCI and for obtaining distinct consequent which can be easily managed in the FIS. A trapezoidal membership function has been used for developing the fuzzy sets for the
Table 2 Parameters for the membership function of input parameters

\begin{tabular}{llll}
\hline Indicators & Low $(a, b, c, d)$ & Average $(a, b, c, d)$ & High $(a, b, c, d)$ \\
\hline FF & $(0,0,3,6)$ & $(3,6,7,10)$ & $(7,10,30,30)$ \\
P & $(0,0,10,17.5)$ & $(10,17.5,22.5,30)$ & $(22.5,30,50$, \\
& & & $50)$ \\
TQI & $(0,0,70,80)$ & $(70,80,85,95)$ & $(85,95,150,150)$ \\
IR & $(0,0,5,10)$ & $(5,10,13,18)$ & $(13,18,50,50)$ \\
\hline
\end{tabular}

FF failure frequency (failure $/ \times 10^{5}$ train $\mathrm{km}$ ), $\mathrm{P}$ punctuality in terms of delay (hours $/ \times 10^{5}$ train $\mathrm{km}$ ), TQI track quality index, IR inspection remarks (remarks $/ \times 10^{8}$ tonnage $\mathrm{km}$ )

composite indices, i.e. very high, high, average, low and very low. The selection of this function is based on its wide use for purposes related to indicator development. It is described by the expression given in Eq. 5. Further, three linguistic terms or fuzzy sets (high, average and low) have been used in the fuzzification of the input parameters based on the existing goal levels set by the infrastructure manager. The trapezoidal membership function in Eq. 5 was used for representing the three fuzzy sets, i.e. high, average and low.

$\mu_{A}(x ; a, b, c, d)=\max \left(\min \left(\frac{x-a}{b-a}, 1, \frac{d-x}{d-c}\right), 0\right)$,

where $A=$ fuzzy set

$$
=\left\{\begin{array}{l}
\text { Output Parameter- Very High, High, Average, Low, Very Low } \\
\text { Input Parameters - High, Average, Low }
\end{array} .\right.
$$

The constant terms $a, b, c$ and $d$ are parameters describing the trapezoidal membership function used in the development of the fuzzy sets. Table 2 shows the parameters of the membership functions used for the input parameters, while Fig. 4 shows the membership function of the FCI. These parameters cover the possible range of value of the indicators and are obtained on the basis of statistics, existing goals and expert opinion.

\section{Case study}

An assessment of the integrity of selected lines on the Swedish transport administration network is carried out using composite performance indicator. The approach described in the previous section is applied to compute the FCI. Some lines are selected to cover the different maintenance regions of the railway administration. The traffic characteristics on the lines differ, as well as boundary conditions such as the weather and local conditions. A brief description of the lines is provided in Table 3. In addition, the capacity situation on the five lines in 2011 as carried out by Wahlborg and Grimm [6] using the conventional view of time table planning and UIC 406 capacity method is presented in Fig. 5. 


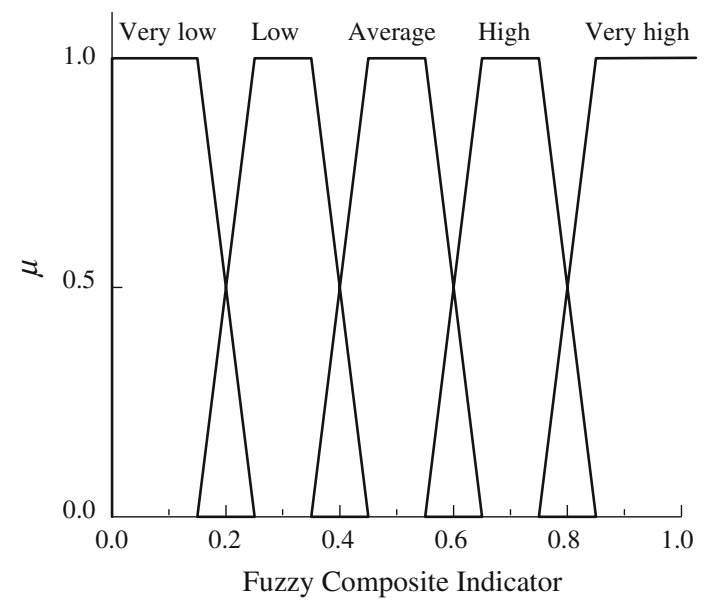

Fig. 4 Membership function for composite indicator

Table 3 Description of selected lines

\begin{tabular}{|c|c|c|c|c|c|c|}
\hline Line & $\begin{array}{l}\text { Maintenance } \\
\text { region }\end{array}$ & $\begin{array}{l}\text { Type } \\
\text { of } \\
\text { traffic }\end{array}$ & $\begin{array}{l}\text { Average } \\
\text { daily } \\
\text { tonnes }\end{array}$ & $\begin{array}{l}\text { Track } \\
(\mathrm{km})\end{array}$ & $\begin{array}{l}\text { Axle } \\
\text { load }\end{array}$ & $\begin{array}{l}\text { Line } \\
\text { class }\end{array}$ \\
\hline $\begin{array}{c}\text { Line } \\
1\end{array}$ & North & $\begin{array}{l}\text { Iron } \\
\text { ore }\end{array}$ & 90,263 & $\begin{array}{l}\text { Single } \\
(125)\end{array}$ & 30 & 2 \\
\hline $\begin{array}{l}\text { Line } \\
2\end{array}$ & North & Mixed & 32,179 & $\begin{array}{l}\text { Single } \\
(175)\end{array}$ & 25 & 3 \\
\hline $\begin{array}{l}\text { Line } \\
3\end{array}$ & East & Mixed & 74,014 & $\begin{array}{l}\text { Double } \\
(59)\end{array}$ & 22 & 2 \\
\hline $\begin{array}{c}\text { Line } \\
4\end{array}$ & West & Mixed & 73,552 & $\begin{array}{r}\text { Double } \\
(231)\end{array}$ & 22 & 2 \\
\hline $\begin{array}{l}\text { Line } \\
5\end{array}$ & South & Mixed & 121,678 & $\begin{array}{r}\text { Double } \\
(102)\end{array}$ & 22 & 1 \\
\hline
\end{tabular}

Line class 1 metropolitan areas, 2 large connecting lines and 3 other important goods and passenger lines

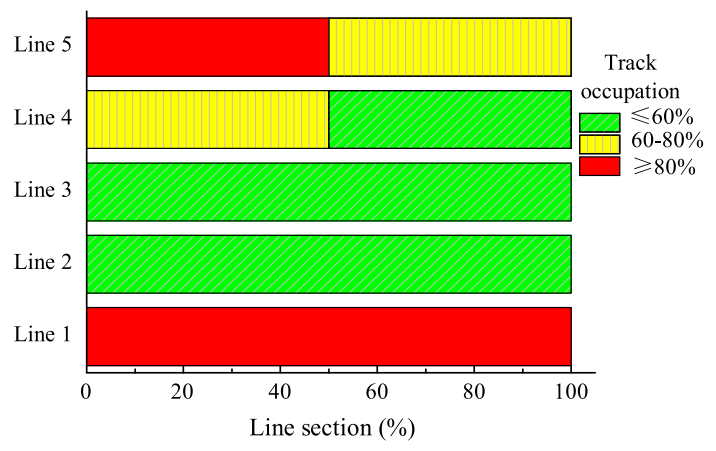

Fig. 5 Capacity condition of the lines in 2011

\section{Results and discussions}

The result of the assessment of health condition of the selected lines using the FIS is presented and discussed below. Figure 6 shows the procedure for computing FCI for one of the lines for the year 2010. Considering FF $=2$, Delay $=13.1$, TQI $=97$ and $\mathrm{IR}=12.8$, only two of the 81 rules are applicable, and the crisp output of the Mamdani FIS is equal to 0.80 .

\subsection{Fuzzy composite indicator}

The procedure shown in Fig. 7 is followed to compute the aggregated non-fuzzy value which is the health value for each of the five lines in the years 2010, 2011 and 2012. The information contained in each indicator is integrated into the fuzzy value to provide an overall picture of the line condition that complements the result of capacity analysis and simulation. The FCI value is graduated from 0 to 1 to reflect the possible variation in the overall state of the line. The value of the FCI is, however, not meant to give detailed information about the physical state of individual components, but rather to check whether there is significant improvement or deterioration in the integrity of the infrastructure. For enhanced visualisation and understanding of the result of the FIS, a customised performance dashboard tool is used for presenting the performance information. These images act as a gateway to scorecards, help in quick problem identification, and accentuate the additional value for the time and resources spent on performance management. Figure 7 shows the performance dashboard for line 4 , giving information on the integrity of the line for the years 2010, 2011 and 2012. The performance dashboard gives the value of the FCI that is an indication of the status of the lines and a measure of capacity limitation. Additional information which can be obtained from the FCI presented in a simplified performance dashboard is the trend of the indicator. An improving trend is shown by an upward arrow in the dashboard, while a deteriorating trend is shown by a downward arrow. It is worth mentioning that the infrastructure manager does not have targets for the FCI for the different lines class yet; thus the level colouration in the performance dashboard is only used for demonstrating possibilities presented by this approach.

Figure 8 presents the fuzzy indicator value for the five lines considered in this article for the year 2012. This simplified presentation of composite indicator gives quick insight into the need for maintenance, renewal or investment on the different lines and is useful for evaluating the overall performance of the maintenance service providers. Adding this information to capacity statement gives a new dimension from infrastructure point of view and helps maintenance service providers to easily convey the need for improvement to strategic decision makers.

Figure 9 shows the computed FCI for the five lines over a period of 3 years. The health value of line 1 is the least and that of line 5 is the highest; these indicate that the infrastructure on line 5 is in good condition and that the 


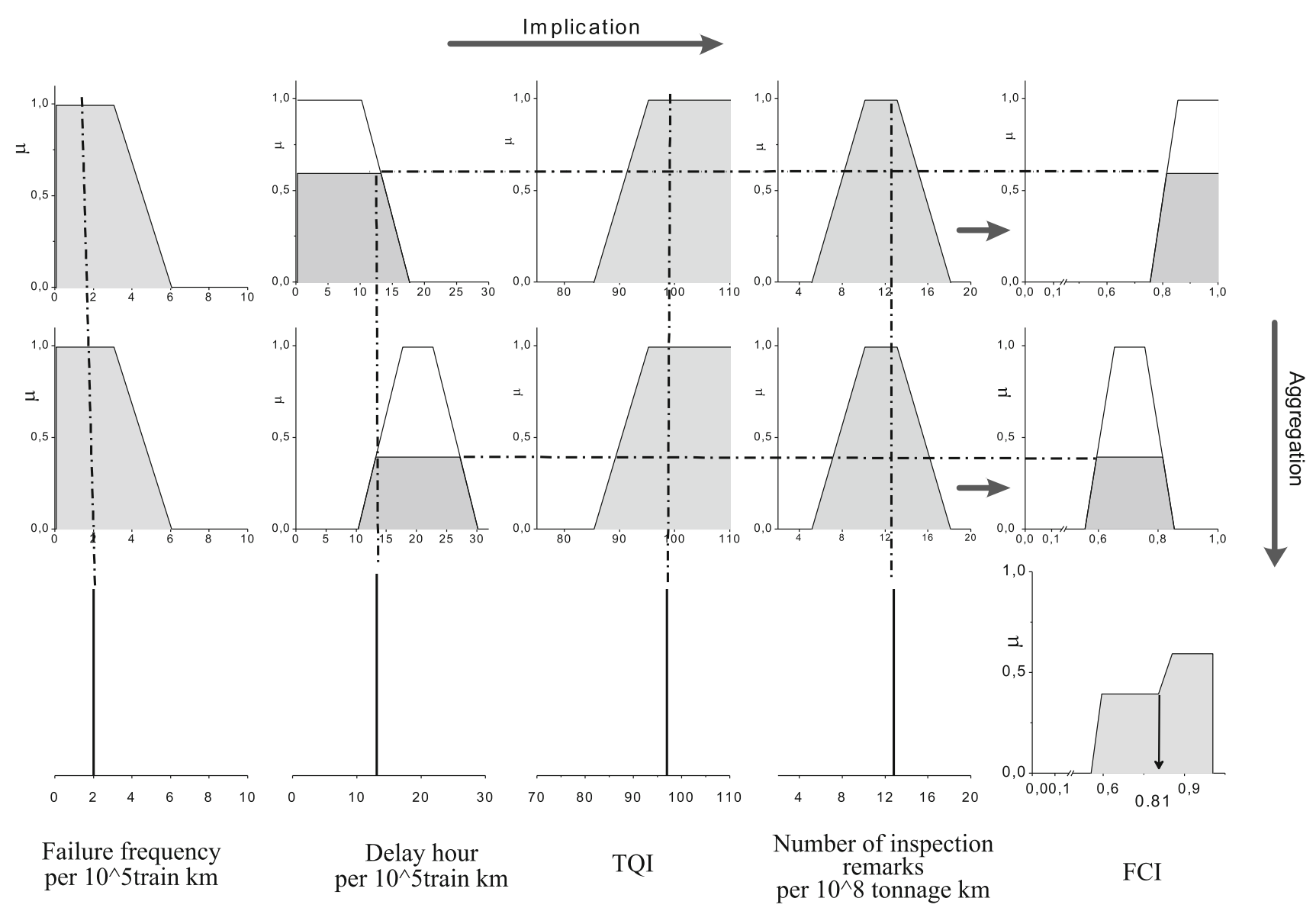

Fig. 6 Computation of FCI using Mamdani FIS
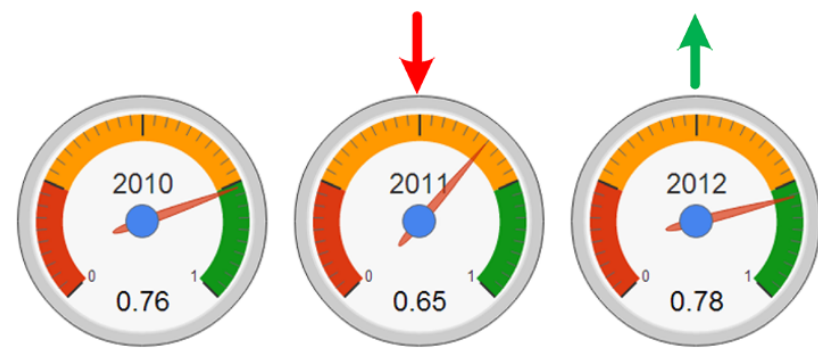

Fig. 7 Performance dashboard for line 4

lines with low FCI require improvement. The conditions of the lines are connected to the following factors: inherent system condition, operating conditions, age and maintenance conditions. The low FCI of line 1 is not only obvious in comparison with other lines, but it is also pronounced in its low value over the 3 years investigated. A reason for this is the heavy haul traffic operated on it and the high capacity utilisation of the line. The integrity of line 1 is basically influenced by its high operation profile; an axle load of 30 tonnes and an average daily traffic volume of 90,000 gross tonnes. The line condition is traffic induced as it is clear that there exists a non-linear relationship between the infrastructure condition and the traffic volume [23]. Another factor which is common with both line 1 and line 2 is the influence of the environmental condition on the state of the lines; these lines are located in the region with harsh winter conditions.

The condition of line 3 apparently got better in 2011, but eventually deteriorated in 2012. Since, maintenance and renewal $(M \& R)$ efforts are often focused on lines with high class and capacity consumption, the conditions of line 2 and line 3 are, therefore, suspected to be low owing to their low capacity consumption. Line 4 is a mixed and double line on the western region and has maintained a health value greater than 0.6 over the 3 years under consideration. Even though the total length of the track is long, the reported failure frequency has been consistently low and the track quality index is high. These make the integrity of the line to be considerably good in relation to the average capacity utilisation, however, if the operational capacity is to be further increased, additional M\&R measures would be required. The condition of line 5 is quite good owing to its high health value that is above 0.8 during 2010, 2011 and 2012. It is a line with more than 200 trains per day and high gross tonnage kilometre, yet the performance or 

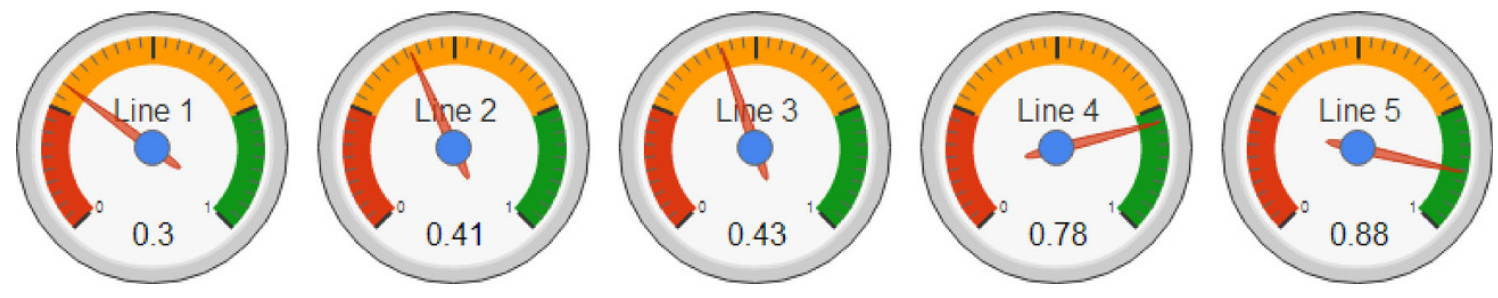

Fig. 8 Presentation of fuzzy composite indices for all the lines for the year 2012 using simple performance dashboard

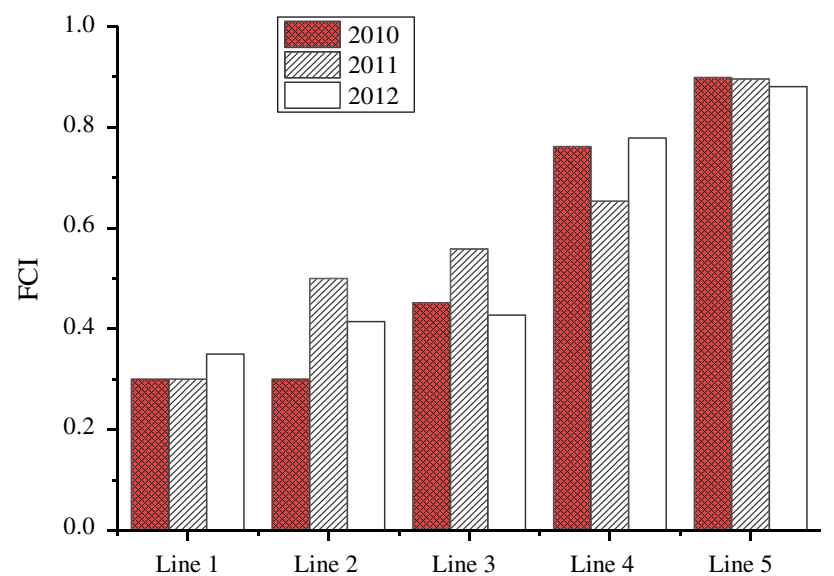

Fig. 9 Composite indicators for five lines

condition of the infrastructure is remarkable. An apparent inference is that the $M \& R$ practice on this line is effective in relation to the capacity condition and could be extended to other lines. Also, the state of the line is an indication that it is ready to accommodate more traffic as long as possible conflicts can be resolved during timetable simulation.

This approach of computing line integrity index complements the conventional capacity analysis methods especially in a format that the maintenance department can appreciate for decision making.

\subsection{Comparison between $\mathrm{FCI}, \mathrm{FF}, \mathrm{CI}_{\mathrm{SAw}}$ and $\mathrm{CI}_{\mathrm{AHP}}$}

There is a need to compare the crisp output from the FIS with some other standard methodologies for computing composite indicators. Basically there is no well-established technique for aggregating indicators for strategic purposes in the railway industries. However, the result of the fuzzy logic approach is compared with failure frequency and also indices obtained from $\mathrm{SAW}\left(\mathrm{CI}_{\mathrm{SAW}}\right)$ and $\mathrm{AHP}\left(\mathrm{CI}_{\mathrm{AHP}}\right)$ approaches.

\subsubsection{FCI and FF}

A common practice in railway transport is to use frequency of traffic interrupting failure of a line for characterising the condition of the infrastructure. Figure 10 shows a quick

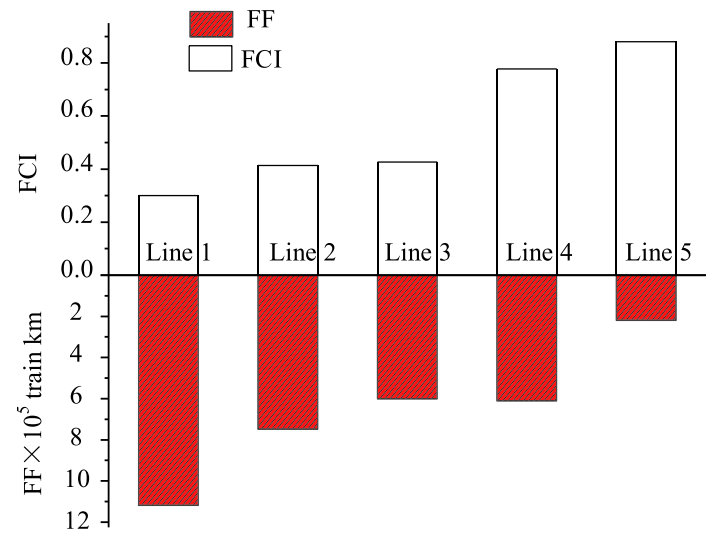

Fig. 10 Comparing failure frequency and fuzzy composite indicator

view of the comparison between FCI and failure frequency (FF) for the year 2010. From the perspective of failure frequency, lines 1 and 5 are both on the extreme positions showing a very high and a very low failure frequency, respectively. This is not expected to change even with contribution from other factors in the fuzzy logic approach. This is supported by Fig. 10, as line 1 has the least fuzzy score, while line 5 has the highest. It gives some level of confidence to the soft computing approach of assessing the integrity of railway infrastructure. Furthermore, the additional information from other indicators used in the computation of FCI makes it a better indication of the line integrity. From the perspective of failure frequency, line 4 has very close condition with lines 2 and 3 . Upon the addition of information on the operational consequence of failure, track quality and inspection remarks as shown in the FCI values, line 4 can be clearly recognised to have better condition and perhaps better M\&R practices.

\subsubsection{FCI and $C I_{S A W}$ and $C I_{A H P}$}

In order to justify and motivate the use of FCI, its result is compared with composite indices obtained from simple additive weighing $\left(\mathrm{CI}_{\mathrm{SAW}}\right)$ and $\mathrm{AHP}\left(\mathrm{CI}_{\mathrm{AHP}}\right)$ methods. In the SAW method, the simple indicators are normalised using inverse min-max function shown in Eq. 6. The same experts used in the fuzzy aggregation rules were involved in the derivation of weights for the different indicators 
using pairwise comparison. The final computation of the composite indicator is done using the expression given in Eq. 7.

$I_{i j}^{t}=1-\frac{X_{i j}^{t}-\min \left(X_{i}^{t}\right)}{\max \left(X_{i}^{t}\right)-\min \left(X_{i}^{t}\right)}$,

$\mathrm{CI}_{\mathrm{SAW}}=\sum_{p=1}^{n} w_{p} I_{i j}^{t}$

where $I_{i j}^{t}$ and $X_{i j}^{t}$ represent the normalised value and actual value of indicator $i$ for line $j$ and year $t$, respectively. $X_{i}^{t}$ represents the actual value of indicator $i$ for all the lines and for the year $t$, whereas $w_{p}$ is the weight of indicator $p$ and $n$ is the total number of indicators.

The AHP combines intuition and logic with data and judgment based on experience. The procedure developed by Saaty [24] is followed and Expert Choice software is used to implement AHP as appropriate in the context of this study. The software is employed to structure the computation process, and measure the importance of constituent indicators using pairwise comparison. It also facilitates the absolute measurement for deriving

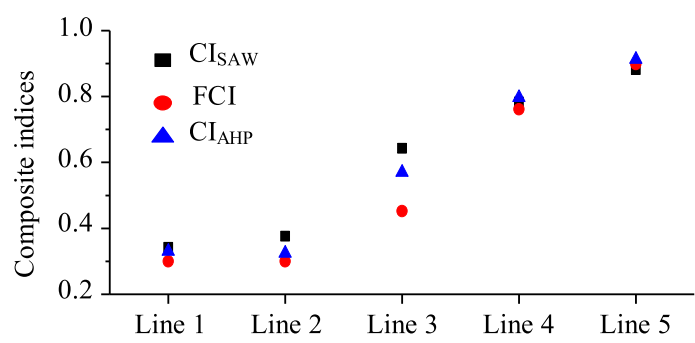

(a) 2010

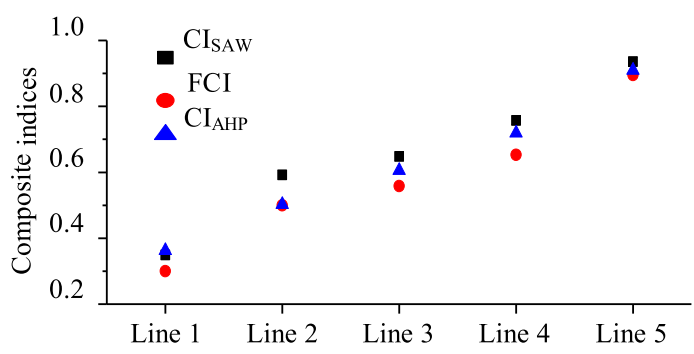

(b) 2011

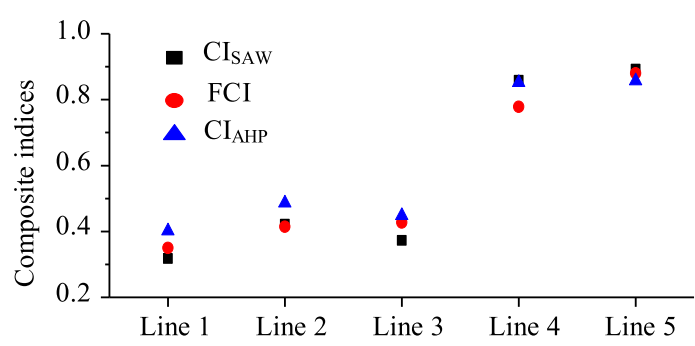

(c) 2012

Fig. 11 Comparing FCI with scores of other aggregation techniques priorities of the selected lines with respect to the indicators. The objective information from data and the subjective judgment of experts are then synthesized to obtain priorities for the lines, these are then regarded as the composite indices $\left(\mathrm{CI}_{\mathrm{AHP}}\right)$ describing the integrity of the lines.

In Fig. 11, the FCI values are compared with the scores of SAW and AHP approaches. The values of the three techniques are quite close especially for line 1 and line 5, where failure frequency, inspection remarks and punctuality show extreme status. It is obvious from Fig. 11 that very similar result will be obtained if the lines were to be ranked based on their integrity using the scores from the three techniques. However, the values obtained using the SAW technique are notably high in some instances due to the problem of compensability (deficit in one dimension is compensated by a surplus in another). Furthermore, the normalisation employed in the SAW approach gives a normalised value of zero to lines with least indicator grade, thus leading to remarkably low values of $\mathrm{CI}_{\mathrm{SAw}}$. The priority value of the AHP technique is appropriate for ranking the lines, but the computation requires review if the values are to be considered as integrity measure of the lines whose evolution is to be analysed. Considering the purpose of the study, FCI approach gives a reliable integrity measure of the lines, since the integrity measure of any line is not relative to other lines, and thus can be monitored over the years. Also the problem of trade-offs or compensability is reduced.

However, the quality of the FCI depends on the experience of the experts and the quality of the data used. There is room for improvement of the quality of the data used in this study. The indicator for punctuality can be extended to cover incidences of cancelled trains due to infrastructure failures. Another important aspect is the need to standardise the inspection strategy in terms of frequency, details and priority classification of inspection remarks on all the lines for reliability sake.

\section{Conclusions}

In this study, we have demonstrated the application of FIS in computing a composite indicator to relate maintenance and renewal function to capacity situation and also to enhance decision making. The proposed FCI will facilitate the assessment of $M \& R$ in terms of infrastructure and traffic performance. This information will support efficient and effective strategic decision making and a longterm infrastructure management plan to increase the operational capacity and service quality of a network. The concluding remarks on the case study presented are as follows: 
- Line 5 has consistently high FCI value that could be considered as effective maintenance and renewal (M\&R) and readiness to accommodate more traffic if other conditions are met. The integrity of line 4 is considerably good in relation to the average capacity utilisation, however, if the operational capacity is to be further increased, additional $M \& R$ measures could be required.

- Line 1 has an undisputedly low FCI value probably because of its heavy operational profile and perhaps inadequate $M \& R$ due to a lack of time to compensate for it. This is an indication for a review of the $M \& R$ strategy to meet the demanding heavy haul on the line.

- Lines 2 and 3 exhibit average FCI over the years, most likely due to low M\&R efforts owing to the low capacity consumption. Increasing the traffic volume will require a raise in the $M \& R$ efforts to maintain a high service quality.

- FCI is a better indication of the line condition than the failure frequency which is the conventional indicator used widely in railway maintenance management.

In future work, the reliability of the proposed indicator would be improved by considering other relevant simple indicators and by applying fuzzy AHP technique for the aggregation.

Acknowledgments We would like to express our sincere gratitude for the financial support of Trafikverket and Luleå Railway Research Centre. Also, we would like to acknowledge Mr Lars Wikberg and Dr Arne Nissen for their support in data collection, as well as Prof. Ashok Deshpande for his technical support.

Open Access This article is distributed under the terms of the Creative Commons Attribution License which permits any use, distribution, and reproduction in any medium, provided the original author(s) and the source are credited.

\section{References}

1. UIC (2004) UIC leaflet 406-capacity. UIC, Paris

2. Abril M, Barber F, Ingolotti L, Salido MA, Tormos P, Lova A (2008) An assessment of railway capacity. Transp Res 44:774-806

3. Krueger H (1999) Parametric modeling in rail capacity planning. Winter Simul Conf Proc 2:1194-1200

4. Landex A (2008) Methods to estimate railway capacity and passenger delays. PhD Dissertation, Department of Transport, Technical University of Denmark

5. Wahlborg M, Grimm M (2014) Railway capacity utilisation and capacity limitation 2013 (järnvägens kapacitetsutnyttjande och kapacitetsbegränsningar 2013). Trafikverket
6. Wahlborg M (1996) Simulation models: important aids for banverket's planning process. Comput Railw 1:175-181

7. Stenström C, Parida A, Galar D (2014) Performance indicators of railway infrastructure. Int J Railw Technol 1(3):1-18

8. Åhrén T, Parida A (2009) Maintenance performance indicators (MPIs) for benchmarking the railway infrastructure: a case study. Benchmarking Int J 16(2):247-258

9. Galar D, Peters R, Stenström C, Berges L, Kumar U (2012). Composite indicators in asset management. 2nd international conference on maintenance performance measurement and management (MPMM), Sunderland

10. Nardo M, Saisana M, Saltelli A, Tarantola S, Hoffman A, Giovannini E (2005) Handbook on constructing composite indicators: methodology and user guide, 3rd edn. OECD publishing, Paris

11. William O, Nuria F, Jose LD, Marta S (2006) Assessing water quality in rivers with fuzzy inference systems: a case study. Environ Int 32:733-742

12. Yadav J, Kharat V, Deshpande A (2011) Fuzzy description of air quality: a case study. Rough Sets and Knowledge Technology, $420-427$

13. Famurewa SM, Asplund M, Parida A, Kumar U (2012). Application of maintenance performance measurement for continuous improvement in the railway industries. The 2 nd international congress on maintenance performance measurement and management (MPMM), Sunderland

14. Neely A (2005) Performance measurement system design: a literature review and research agenda. Int $\mathbf{J}$ Oper Prod Manag 25(12):1228-1263. doi:10.1108/01443570510633639

15. Parida A, Chattopadhyay G (2007) Development of a multi-criteria hierarchical framework for maintenance performance measurement (MPM). J Qual Maint Eng 13(3):241-258

16. Trafikverket (2005) Safety inspections of infrastructure (säkerhetsbesiktning av fasta anläggningar, BVF 807.2). Trafikverket, Banverket

17. Lee CC (1990) Fuzzy logic in control systems: fuzzy logic controller. I. Systems, man and cybernetics. IEEE Trans 20(2):404-418

18. Ross TJ (2009) Fuzzy logic with engineering applications. Wiley, Chichester

19. Zadeh LA (1973) Outline of a new approach to the analysis of complex systems and decision processes. Systems, man and cybernetics. IEEE Trans 1:28-44

20. Zadeh LA (1996) Fuzzy logic = computing with words. Fuzzy systems. IEEE Trans 4(2):103-111

21. Al-Najjar B, Alsyouf I (2003) Selecting the most efficient maintenance approach using fuzzy multiple criteria decision making. Int J Prod Econ 84(1):85-100

22. Sivanandam $S$, Sumathi $S$, Deepa $S$ (2006) Introduction to fuzzy logic using MATLAB. Springer, Heidelberg

23. Lyngby N, Hokstad P, Vatn J (2008) RAMS management of railway tracks. In: Misra KB (ed) Handbook of performability engineering. Springer, London, pp 1123-1145

24. Saaty TL (2008) Decision making with the analytic hierarchy process. Int J Serv Sci 1(1):83-98

25. prEN-13848-6 (2012) Railway applications-track-track geometry quality-part 6: characterisation of track geometry quality. European Committee for Standardization (CEN), Brussels 